\title{
Prevalence of vancomycin resistant Enterococci and associated risk factors among clients with and without HIV in Northwest Ethiopia: a cross-sectional study
}

Wondwossen Abebe, Mengistu Endris, Moges Tiruneh and Feleke Moges ${ }^{*}$

\begin{abstract}
Background: Enterococci are the most important multidrug resistant organisms associated with immunocompromised patients. Data are lacking about the epidemiology of vancomycin resistant Enterococci (VRE) in Ethiopia. This study aimed to assess the prevalence of VRE, their susceptibility patterns to different antibiotics and associated risk factors in fecal samples of Human Immunodeficiency Virus (HIV) positive and HIV negative clients.

Methods: A cross sectional study was carried out in a total of 226 (113 HIV positive and 113 HIV negative) clients, from July 1/2013 to September 30/2013 at the University of Gondar Teaching Hospital. Data on socio-demographic characteristics and risk factors were collected with a short interview guided by pre-tested structured questionnaire. The enterococci were isolated and identified from stool sample using standard bacteriological procedures. Kary Bauer disk diffusion method was used to determine the susceptibility patterns of Enterococci isolates. Data were entered and analyzed using SPSS version 20 statistical package.
\end{abstract}

Results: The overall colonization of Enterococci was 88.9\% (201/226) of which 11 (5.5\%) were VRE. The prevalence of VRE among clients with and without HIV infections were $8(7.8 \%)$ and 3(3.1\%), respectively. Ninety percent of the Enterococci isolates (181/201) were resistant to two or more antibiotics tested. Isolates of Enterococci recovered from stool samples of HIV infected patients were more resistant to amoxicillin and amoxicillin-calvulinic acid than HIV negative clients $(P<0.05)$. Antibiotic treatment for the last 2 weeks was found to be the risk factor that showed statistically significant association with the presence of high VRE colonization. However, the socio-demographic variables and factors such as malnutrition, leucopenia, thromobocytopenia, anaemia, duration of Highly Active Antiretroviral Therapy, CD4 cell count, stage of WHO and drinking alcohol were not associated with VRE (P > 0.05).

Conclusion: The high prevalence of VRE in this study signals the emergence of VRE in the study area. Prior antibiotic treatment was associated with VRE colonization. Therefore, rational use of antibiotics and more detailed study using phenotypic and genotypic methods are needed.

Keywords: Vancomycin-resistant, Enterococcci, HIV

* Correspondence: Mogesfeleke@gmail.com

Department of Medical Microbiology, University of Gondar, Gondar, Ethiopia 


\section{Background}

Enterococci are normal inhabitants of the gastrointestinal tract of humans and animals. Two species cause most enterococcal infections, Enterococcus faecalis and E. faecium. Enterococci cause urinary tract infections mainly followed by intra-abdominal and pelvic infections. They also cause surgical wound infections, bacteraemia, endocarditis, neonatal sepsis and rarely meningitis [1].

Among the risk factors, previous antibiotic treatment [2], duration of hospitalization ( $\geq 7$ days), and duration of vancomycin use ( $\geq 7$ days) [3], surgical units or intensive-care units; co-morbidities such as diabetes, renal failure; and the presence of a urinary catheter [4], are among the many risk factors for colonization or infection with vancomycin resistance Enterococci (VRE). Critically ill patients or those with severe underlying disease or immunosuppression such as persons who have had an intra abdominal or cardio-thoracic surgical procedure or an indwelling urinary or central venous catheter are also important risk factors [5]. Moreover, HIV-positive patients often receive antibiotic therapy and have frequent contact with the healthcare system, both of which are factors that have been associated with an increased risk of infection with VRE in other populations [6].

The relative importance of Enterococcus as a pathogen has increased with the occurrence of high-level resistance to multiple antimicrobial drugs, such as ampicillin and vancomycin [7]. The emergence of VRE has alarmed the global infectious diseases community due to few option left for disease management, resistance gene transfer from Enterococci to Staphylococcus aureus and presence of different selection pressures for VRE proliferation and rapid expansion of resistant populations [8]. The prevalence of VRE was reported in Europe, Asia, Australia, South America and some countries of Africa [9]. However, there is no enough data available on the epidemiology and risk factors of VRE in Ethiopia. The present study aimed to assess the prevalence of VRE, their susceptibility patterns to different antibiotics and associated risk factors in fecal samples of HIV positive and HIV negative clients at the University of Gondar Teaching Hospital.

\section{Methods}

\section{Study design, area and period}

A cross sectional study was carried out from July 1/ 2013 to September 30/2013 at the University of Gondar Teaching Hospital. The hospital is located in Gondar town, $737 \mathrm{~km}$ Northwest of Addis Ababa. It has 400 beds and provides health care referral services for over 5 million inhabitants in Northwest Ethiopia. The University Teaching hospital has ART clinic and blood bank center.

\section{Study population}

HIV positive patients attending ART clinic and HIV negative blood donors at the University of Gondar Teaching Hospital during the study period were enrolled in this study.

\section{Sample size and sampling technique}

The sample size was determined by using EPI INFO version 3.5.3 in double population proportion. Since there is no previous study done in this area, $50 \%$ prevalence was used for HIV negative clients. HIV positive patients are assumed to have 20\% more VRE carriage than HIV negative clients, $70 \%$. Considering the two prevalence, power $80 \%$ at $95 \%$ confidence with 1:1 ratio the final sample size was 226 (113 HIV infected patients and 113 HIV negative blood donors). The last 3 years hospital report showed that an average of $57 \mathrm{HIV}$ positive clients was visited the ART laboratory daily. We calculated the total participants in 3 months study period $(57 \times 90$ days $=5130)$. Since our sample size is $113 \mathrm{HIV}$ positive patients we calculated the $\mathrm{k}=$ value to be 45 . The first one was selected with lottery method from 1-45 cases. Then every $45^{\text {th }}$ patients were included in this study. Consecutive HIV negative volunteers blood donors $(n=113)$ were also included in the study.

\section{Data collection}

Socio-demographic and clinical data and other possible factors responsible for colonization of VRE such as antimicrobial therapy, drinking alcohol and others were collected using pre-tested structured questionnaire. Five milliliters of blood was drawn from each client by an experienced laboratory technologist. The HIV status of the clients was determined using rapid test kit (KHB, STAT pak and Uni-Gold) following the current Ethiopian algorithm [10]. The $\mathrm{CD}_{4}$ count (for HIV positives) and complete blood count were done using BD FACS count and Sysmex Machine respectively.

\section{Stool sample collection and processing}

The clients were provided with wide-mouthed, sterile plastic containers and informed to submit stool specimens. The collected stool specimens were streaked on Bile Esculin Azide agar (Hardy Diagnostics, Santa Maria, CA, USA) and incubated for 24 hours at $37^{\circ} \mathrm{C}$. Plates were observed for appearance of characteristic colonies of growth and blackening. Typical characteristic colonies were selected randomly for characterization and presumptive identification of Enterococcci [11]. Each isolate was also assessed using Gram staining, catalase test and its growth in $6.5 \% \mathrm{NaCl}$ broth. Presumptive pure colonies were picked and inoculated into Brain Heart Infusion (BHI) broth, and incubated at $45^{\circ} \mathrm{C}$ for 24 hours and growth in the medium was assessed by its turbidity. 
An isolate fulfilling the above criteria was assumed to be Enterococccus species [11].

\section{Antimicrobial susceptibility testing}

Antimicrobial susceptibility testing for each isolate was done using Muller-Hinton agar (OXOID, UK) disc diffusion method [12]. Antimicrobial susceptibility patterns of Enterococci were assessed against nine antibiotic discs (all OXOID, UK). These were vancomycin $30 \mu \mathrm{g}$, ampicillin $10 \mu \mathrm{g}$, amoxicillin $10 \mu \mathrm{g}$, amoxicillin-clavulinic acid $10 \mu \mathrm{g}$, ciprofloxacin $5 \mu \mathrm{g}$, chloramphenicol $30 \mu \mathrm{g}$, erythromycin $15 \mu \mathrm{g}$, gentamicin $10 \mu \mathrm{g}$ and trimethoprimsulfamethoxazole $1.25 / 23.75 \mu \mathrm{g}$.

\section{Quality control}

Reference strain of Staphylococcus aureus ATCC 25923 and E. faecalis ATCC 51299 were used as negative and positive control, respectively.

\section{Data analysis}

Data were entered and analyzed using SPSS version 20. Descriptive statistics were employed and odds ratio (OR) was used to determine the strength of association. Multivariate analysis using logistic regression model was used to analyze the association between VRE colonization and potential risk factors. Those variables with over all $P$ value less than 0.2 in the bivariate analysis were entered into multivariate analysis. P-values $<0.05$ was considered statistically significant.

Definitions: Leukocytosis and leucopenia were defined as having WBC count greater than $12,000 / \mathrm{mm} 3$ and less than $4,000 / \mathrm{mm} 3$, respectively. A client was named as thrombocytopenic when she/he had a platelet count of $<100,000 / \mu \mathrm{L}$.

\section{Ethical consideration}

The study was approved by the research and ethics committee of the School of Biomedical and Laboratory

Table 1 Socio-demographic characteristics of clients with and without HIV at the University of Gondar Teaching Hospital, Northwest Ethiopia, 2013

\begin{tabular}{|c|c|c|c|}
\hline \multirow{3}{*}{$\begin{array}{l}\text { Socio-demographic } \\
\text { characteristics }\end{array}$} & \multicolumn{2}{|l|}{ HIV status } & \multirow{3}{*}{$\begin{array}{l}\text { All }(n=226) \\
\text { Number (\%) }\end{array}$} \\
\hline & Negative $(n=113)$ & Positive $(n=113)$ & \\
\hline & Number (\%) & Number (\%) & \\
\hline \multicolumn{4}{|l|}{ Sex } \\
\hline Male & $70(61.9)$ & $53(46.9)$ & $123(54.4)$ \\
\hline Female & $43(38.1)$ & $60(53.1)$ & $103(45.6)$ \\
\hline Mean (SD) Age (range) & $35.12 \pm 10.85(19-66)$ & $36.12 \pm 8.05(23-65)$ & $35.62 \pm 9.54(19-66)$ \\
\hline \multicolumn{4}{|l|}{ Age (years) } \\
\hline $11-20$ & $7(6.2)$ & $0(0)$ & $7(3.1)$ \\
\hline $21-30$ & $39(34.5)$ & $35(31.1)$ & $74(32.7)$ \\
\hline $31-40$ & $43(38.1)$ & $53(46.9)$ & $96(42.5)$ \\
\hline $41-50$ & $15(13.3)$ & $21(18.6)$ & $36(15.9)$ \\
\hline $51-60$ & $6(5.3)$ & $3(2.7)$ & $9(4.0)$ \\
\hline $61+$ & $3(2.1)$ & $1(0.9)$ & $4(1.8)$ \\
\hline \multicolumn{4}{|l|}{ Education status } \\
\hline Illiterate & $21(18.6)$ & $31(27.4)$ & $52(23.0)$ \\
\hline Literate & $92(81.4)$ & $82(72.6)$ & $174(77.0)$ \\
\hline \multicolumn{4}{|l|}{ Residence } \\
\hline Urban & $103(91.2)$ & $110(97.3)$ & $213(94.2)$ \\
\hline Rural & $10(8.8)$ & $3(2.7)$ & $13(5.8)$ \\
\hline \multicolumn{4}{|l|}{ Marital status } \\
\hline Single & $46(40.7)$ & $23(20.4)$ & $69(30.5)$ \\
\hline Married & $64(56.6)$ & $51(45.1)$ & $115(50.9)$ \\
\hline Widowed & $2(1.8)$ & $14(12.4)$ & $16(11.5)$ \\
\hline Divorced & $1(0.9)$ & $25(22.1)$ & $26(7.1)$ \\
\hline
\end{tabular}


Table 2 Prevalence of VRE among clients with and without HIV at the University of Gondar Teaching Hospital, Northwest Ethiopia, 2013

\begin{tabular}{|c|c|c|c|c|c|}
\hline \multirow{3}{*}{$\begin{array}{l}\text { HIV } \\
\text { status }\end{array}$} & \multirow[t]{3}{*}{ Total } & \multicolumn{2}{|l|}{ Enterococci } & \multirow[t]{3}{*}{ OR $(95 \% \mathrm{Cl})$} & \multirow[t]{3}{*}{ P-value } \\
\hline & & VRE & VSE & & \\
\hline & & $\overline{\text { Number (\%) }}$ & Number (\%) & & \\
\hline Positive & $103(51.2)$ & $8(7.8)$ & $95(92.2)$ & $2.67(0.62-13.12)$ & 0.14 \\
\hline Negative & $98(48.8)$ & $3(3.1)$ & 95(96.9) & 1.00 & \\
\hline Total & $201(100)$ & $11(5.5)$ & $190(94.5)$ & & \\
\hline
\end{tabular}

VRE = Vancomycin resistant Enterococci; VSE = Vancomycin Sensitive Enterococci.

Sciences, University of Gondar. Written informed consent was also obtained from each client.

\section{Results}

Socio-demographic characteristics of the clients

A total of 226 (113 HIV positive and113 HIV negative) clients were included in this study. One hundred and twenty three (54.4\%) were males and 103 (45.6\%) were females. The mean age and standard deviation was $35.62 \pm 9.54$ ranged from $19-66$ years. Majority of the clients were literate $174(77.0 \%)$ and urban residents 213 (94.2\%) (Table 1).

\section{Prevalence of VRE among HIV positive and HIV negative clients}

Among 226 clients growth of Enterococcus species was seen in 201 (88.9\%) stool specimens. The colonization of Enterococci among HIV positives and HIV negatives clients was $103(91.2 \%)$ and 98 (86.7\%), respectively. There was no statistically significant difference in the isolation frequency of Enterococci among clients with and without HIV infection $(\mathrm{P}=0.29)$.

Among the 201 isolates of Enterococci in this study, 11 (5.5\%) were VRE. The prevalence of VRE among HIV positive and HIV negative clients was 8 (7.8\%) and 3 (3.1\%), respectively. No significant association was observed between VRE and HIV sero-status ( $\mathrm{P}=0.14$; $\mathrm{OR}=2.67 ; 95 \% \mathrm{CI}=0.62-13.12$ ) (Table 2).

\section{Antimicrobial susceptibility pattern of Enterococcci}

One hundred eighty one (90\%) isolates were resistant to two or more antimicrobials tested. Among 201 Enterococci isolates tested 113 (56.2\%) were resistant to amoxicillin. The amoxicillin resistance Enterococci were 65 (63.1\%) and 48 (42.5\%) among HIV positives and HIV negative clients, respectively. Fifty five isolates (27.4\%) of Enterococci were resistant to amoxacillin-clavulinic acid, of which, 35 (33.9\%) and 20 (20.4\%) were from HIV positives and HIV negatives, respectively. There was statistically significant difference of resistance to amoxicillin, amoxacillin-clavulinic acid and erythromycine between isolates from HIV positive and HIV negative clients $(\mathrm{P}<$ 0.05). However, no statistically significant differences were observed in resistance pattern for the antibiotics: ampicillin, chloroamphinicol, ciprofloxacillin, gentamycine, sulphamethaxozole and vancomycin in HIV positives and HIV negative clients $(\mathrm{P}>0.05)$ (Table 3 ).

All isolates of VRE were multidrug resistant and all isolates of VRE in HIV positive patients were resistant to Ampicillin, Amoxacillin and Gentamycin while in HIV negative patients all isolates of VRE were

Table 3 Antimicrobial resistance patterns among clients with and without HIV at the University of Gondar Teaching Hospital, Northwest Ethiopia, 2013

\begin{tabular}{|c|c|c|c|c|c|}
\hline \multirow[t]{2}{*}{ Resistant to antibiotics } & \multirow{2}{*}{$\frac{\text { HIV positive } \mathrm{N}=103}{\text { Number }(\%)}$} & \multirow{2}{*}{$\frac{\text { HIV Negative } \mathrm{N}=98}{\text { Number (\%) }}$} & \multirow{2}{*}{$\frac{\text { Total } N=201}{\text { Number (\%) }}$} & \multirow[t]{2}{*}{$x^{2}$} & \multirow[t]{2}{*}{$\overline{P \text {-value }}$} \\
\hline & & & & & \\
\hline Ampicillin & $80(77.7)$ & $80(81.6)$ & $160(79.6)$ & 0.27 & 0.49 \\
\hline Amoxacillin & $65(63.1)$ & $48(48.9)$ & $113(56.2)$ & 4.07 & 0.04 \\
\hline Amoxacillin-clavulinic acid & $35(33.9)$ & $20(20.4)$ & $55(27.4)$ & 4.65 & 0.03 \\
\hline Chloroamphinicol & $13(12.6)$ & $12(12.4)$ & $25(12.4)$ & 0.01 & 0.94 \\
\hline Ciprofloxacillin & $41(39.8)$ & $27(27.5)$ & $68(33.8)$ & 3.37 & 0.06 \\
\hline Erythromycine & $58(56.3)$ & $69(70.4)$ & $127(63.2)$ & 4.29 & 0.07 \\
\hline Gentamycine & $73(70.8)$ & $71(72.4)$ & $144(71.6)$ & 0.06 & 0.80 \\
\hline Sulphamethaxazole & 45(43.6) & 48(48.9) & $93(46.4)$ & 0.57 & 0.45 \\
\hline Vancomycine & $8(7.7)$ & $3(3.1)$ & $11(5.5)$ & 2.15 & 0.14 \\
\hline MDR & $91(92.8)$ & $90(91.8)$ & $181(90)$ & 0.68 & 0.41 \\
\hline
\end{tabular}


Table 4 VRE $(n=11)$ isolates resistant patterns among clients with and without HIV at the University of Gondar Teaching Hospital, Northwest Ethiopia, 2013

\begin{tabular}{|c|c|c|c|}
\hline \multirow[t]{2}{*}{ Resistant to antibiotics } & HIV positive $\mathrm{N}=8$ & HIV Negative $\mathrm{N}=3$ & Total $\mathrm{N}=11$ \\
\hline & Number (\%) & Number (\%) & $\overline{\text { Number (\%) }}$ \\
\hline Ampicillin & $8(100)$ & $3(100)$ & $11(100)$ \\
\hline Amoxacillin & $8(100)$ & $1(33.3)$ & $9(81.8)$ \\
\hline Amoxacillin-clavulinic acid & $5(62.5)$ & $1(33.3)$ & $6(54.5)$ \\
\hline Chloroamphinicol & $3(37.5)$ & $2(66.7)$ & $5(45.5)$ \\
\hline Ciprofloxacillin & $2(25)$ & $2(66.7)$ & $4(36.4)$ \\
\hline Erythromycin & $7(87.5)$ & $3(100)$ & $10(90.9)$ \\
\hline Gentamycin & $8(100)$ & $2(66.7)$ & $10(90.9)$ \\
\hline Trimethoprim-sulfamethoxazole & $4(50)$ & $3(100)$ & $7(63.6)$ \\
\hline MDR & $8(100)$ & $3(100)$ & $11(100)$ \\
\hline
\end{tabular}

resistant to Ampicillin, Erythromycin and Trimethoprimsulfamethoxazole (Table 4).

\section{Associated risk factors with VRE}

Majority of VRE was isolated from females, age $>31$ years and urban residents. No significant association between
VRE and socio-demographic characteristics such as, age, sex, educational status, marital status and residence (P > 0.05) (Table 5).

Prevalence of VRE was significantly associated with antibiotic treatment more than 2 weeks $(\mathrm{P}=0.01$; $\mathrm{AOR}=$ $10.21 ; 95 \% \mathrm{CI}=1.31-217.40)$. However, it was not

Table 5 Socio-demographic characterstics and prevalence of VRE with and without HIV at the University of Gondar Teaching Hospital, Northwest Ethiopia, 2013

\begin{tabular}{|c|c|c|c|c|}
\hline \multirow{3}{*}{$\begin{array}{l}\text { Socio- } \\
\text { demographic } \\
\text { characteristic }\end{array}$} & \multicolumn{2}{|l|}{$\underline{\text { VRE }(n=11)}$} & \multirow{3}{*}{$\begin{array}{l}\text { P- } \\
\text { value }\end{array}$} & \multirow[t]{3}{*}{ OR (95\% Cl) } \\
\hline & HIV positive & HIV negative & & \\
\hline & No. (\%) & No. (\%) & & \\
\hline \multicolumn{5}{|l|}{ Sex } \\
\hline Male & $3(60.0)$ & $2(40.0)$ & - & 1.00 \\
\hline Female & $5(83.3)$ & $1(16.7)$ & 0.54 & $3.33(0.12-156)$ \\
\hline \multicolumn{5}{|l|}{ Age (years) } \\
\hline $11-20$ & $0(0)$ & $0(0)$ & NA & NA \\
\hline $21-30$ & $2(100)$ & $0(0)$ & - & 1.00 \\
\hline $31-40$ & $4(80.0)$ & $1(20.0)$ & 0.71 & $0.00(0-76.65)$ \\
\hline $41-50$ & $2(50.0)$ & $2(50.0)$ & 0.40 & $0.00(0-14.83)$ \\
\hline $51-60$ & $0(0)$ & $0(0)$ & NA & NA \\
\hline $61+$ & $0(0)$ & $0(0)$ & NA & NA \\
\hline \multicolumn{5}{|l|}{ Education status } \\
\hline Illiterate & $1(33.3)$ & $2(66.7)$ & 0.15 & $0.07(0.00-2.88)$ \\
\hline Literate & $7(87.5)$ & $1(12.5)$ & - & 1.00 \\
\hline \multicolumn{5}{|l|}{ Residence } \\
\hline Urban & $7(70.0)$ & $3(30.0)$ & - & 1.00 \\
\hline Rural & $1(100)$ & $0(0)$ & 0.73 & UD \\
\hline \multicolumn{5}{|l|}{ Marital status } \\
\hline Single & $1(100)$ & $0(0)$ & - & 1.00 \\
\hline Married & $4(57.1)$ & $3(42.9)$ & 0.62 & $0.00(0-40.29)$ \\
\hline Widowed & $2(100)$ & $0(0)$ & NA & NA \\
\hline Divorced & $1(100)$ & $0(0)$ & NA & NA \\
\hline Over all & $8(72.7)$ & $3(27.3)$ & 0.14 & $2.67(0.62-13.12)$ \\
\hline
\end{tabular}


associated with HAART, duration of HAART, $\mathrm{CD}_{4}$ cell count, WBC counts, platelet counts, nutritional status, WHO stage, drinking alcohol habit and anemic status (Table 6).

\section{Discussion}

In the present study the overall prevalence of Enterococci was $201 / 226(88.9 \%)$. This was consistent with the previous report from Israel 88.5\% [13]. However, it was lower

Table 6 Risk factors of VRE among HIV positive and HIV negative clients at Gondar University Teaching Hospital, Northwest Ethiopia, 2013

\begin{tabular}{|c|c|c|c|c|c|}
\hline \multirow[t]{3}{*}{ Risk factors } & \multicolumn{2}{|l|}{ Enterococci } & \multirow{3}{*}{$\begin{array}{l}\text { Total } \\
\text { Number } \\
\text { (\%) }\end{array}$} & \multirow[t]{3}{*}{ P-value } & \multirow[t]{3}{*}{ AOR $(95 \% \mathrm{Cl})$} \\
\hline & \multirow{2}{*}{$\begin{array}{l}\text { VRE } \\
\text { Number (\%) } \\
\end{array}$} & \multirow{2}{*}{$\frac{\text { VSE }}{\text { Number (\%) }}$} & & & \\
\hline & & & & & \\
\hline \multicolumn{6}{|c|}{ Antibiotic treatment ( $>2$ weeks) } \\
\hline Yes & $10(9.6)$ & $94(90.4)$ & $104(51.7)$ & 0.01 & $10.21(1.31-217.40)$ \\
\hline No & $1(1.0)$ & $96(99.0)$ & $97(48.3)$ & - & 1.00 \\
\hline \multicolumn{6}{|l|}{$\mathrm{CD}_{4}^{*}$} \\
\hline$\leq 350$ & $5(11.4)$ & $39(88.6)$ & $44(42.7)$ & 0.21 & $2.39(0.46-13.57)$ \\
\hline$>350$ & $3(5.1)$ & $56(94.9)$ & $59(57.3)$ & - & 1.00 \\
\hline \multicolumn{6}{|l|}{ HAART } \\
\hline Yes $^{*}$ & $8(7.8)$ & $94(92.2)$ & $102(50.7)$ & 0.13 & $2.72(0.63-13.40)$ \\
\hline No & $3(3.0)$ & $96(97.0)$ & $99(49.3)$ & - & 1.00 \\
\hline \multicolumn{6}{|c|}{ HAART Duration (Year) ${ }^{*}$} \\
\hline$\leq 2$ & $2(6.7)$ & $28(93.3)$ & $30(29.1)$ & - & 1.00 \\
\hline$>2$ & $6(8.2)$ & $67(91.8)$ & $73(70.9)$ & 0.57 & $1.25(0.21-9.62)$ \\
\hline \multicolumn{6}{|l|}{ WBC counts } \\
\hline Normal & $11(6.6)$ & $156(93.4)$ & $167(83.1)$ & - & 1.00 \\
\hline Leucopenic & $0(0)$ & $27(100)$ & $27(13.4)$ & 0.18 & $0.00(0.00-2.92)$ \\
\hline Leucocytosis & $0(0)$ & $7(100)$ & $7(3.5)$ & 0.62 & $0.00(0.00-12.95)$ \\
\hline \multicolumn{6}{|l|}{ Platelet } \\
\hline Normal & $10(5.6)$ & $168(94.4)$ & $188(88.6)$ & - & 1.00 \\
\hline Thrombocytopenic & $0(0)$ & $12(100)$ & $12(6.0)$ & 0.51 & $0.00(0.00-8.40)$ \\
\hline Thrombocytosis & $1(9.1)$ & $10(90.9)$ & $11(5.4)$ & 0.49 & $1.68(\mathrm{NA})$ \\
\hline \multicolumn{6}{|l|}{ Nutritional status } \\
\hline Normal & $8(4.7)$ & $161(95.3)$ & $169(84.1)$ & - & 1.00 \\
\hline Malnourished & $2(13.3)$ & $13(86.7)$ & $15(7.5)$ & 0.19 & $3.10(0.41-18.57)$ \\
\hline Overweight & $1(5.9)$ & $16(94.1)$ & $17(8.5)$ & 0.59 & $1.26(\mathrm{NA})$ \\
\hline \multicolumn{6}{|l|}{ Anemic } \\
\hline Yes & $11(5.8)$ & $179(94.2)$ & $190(94.5)$ & 0.52 & UD \\
\hline No & $0(0)$ & $11(100)$ & $11(5.5)$ & - & 1.00 \\
\hline \multicolumn{6}{|l|}{ Drinking alcohol } \\
\hline Yes & $2(3.4)$ & 57 (96.6) & $59(29.4)$ & 0.32 & $0.52(0.07-2.69)$ \\
\hline No & $9(6.3)$ & $133(93.7)$ & 142 (70.6) & - & 1.00 \\
\hline \multicolumn{6}{|l|}{ WHO stage ${ }^{*}$} \\
\hline I & $2(8.3)$ & $22(91.7)$ & $24(23.3)$ & - & 1.00 \\
\hline$\|$ & $0(0)$ & $15(100)$ & $15(14.6)$ & 0.37 & $0.00(0.00-6.91)$ \\
\hline III & $2(6.7)$ & $28(93.3)$ & $30(29.1)$ & 0.60 & $0.79(0.07-8.68)$ \\
\hline IV & $4(11.8)$ & $30(88.2)$ & $34(33.3)$ & 0.51 & $\begin{array}{l}1.47 \\
0.20-12.82)\end{array}$ \\
\hline
\end{tabular}


than a report from Algeria (100\%) [14]. This variation in colonization might be due to the advanced molecular method in the previous study.

The prevalence of Enterococci was higher in HIV positives $(91.2 \%)$ than HIV negatives $(86.7 \%)$ clients. However, this was not statistically significant $(P=0.14)$. This result was in line with reports by Hijazi [15] in hospitalized patients (94\%) and in individuals living in the community (89\%).

The prevalence of VRE in this study was 11/201(5.5\%). This was consistent with reports from Korea, 4.5\% [16] and lower than reports from Egypt (25\%) isolated from pediatric patients [17] and health care workers in intensive care units (9.5\%) [18]. These differences might be due to the study design and study participants (pediatric age and intensive care unit) in the previous study.

The prevalence of VRE among HIV positives (7.8\%) in the present study was higher than reports from USA, $0 \%$ [19] and 4.7\% [6]. This variation might be due to difference in the study population where most of the clients in the present study had habit of animal contact and this was supported by Bekele and Ashenafi, reported as 100\% VRE Enterococci isolated from faeces of chicken and cattle in Ethiopia [20]. Comparison of colonization of VRE among HIV positives $(7.8 \%)$ and HIV negative (3.1\%) clients' revealed that there was a slightly higher VRE in HIV positive patients. The higher VRE among HIV positives might be due to repeated exposure to different antibiotics [6] and immune-suppression [21] which are important risk factors for colonization or infection with VRE.

Among risk factors studied for VRE, a patient with a history of prior antibiotic use was found to be important factor $(P=0.01)$. Similar reports from Iran showed that antibiotic exposure can cause the emergence of VRE by inducing the expression of resistance genes and by selecting strains already expressing these genes and altering the competing microbial flora in the GI tract, thereby increasing VRE concentration in the stools [22,23]. However, stool consistency, CD4+ count, HARRT, HARRT duration (year),WBC and platelet count, nutritional status, anaemia, drinking alcohol, WHO stage for HIV were not statistically significant risk factors for VRE $(\mathrm{P}>0.05)$. This was consistent with previous study in USA [6].

Among 201 isolates of Enterococci 181 (90\%) were resistant to two or more antibiotics tested. Similarly over $80 \%$ of multiple drug resistance (MDR) Enterococci isolates were reported from cattle in Addis Ababa [20]. Although high percentage of resistance against ampicillin (79.6), gentamaycin (71.6) and erythromycin (63.2) were observed, no significant difference was seen between HIV positive and HIV negative clients. However, the resistance pattern of Enterococcus isolates to amoxicillin and amoxicillin-clavulinic acid were significantly higher in HIV positive than HIV negative clients. This significant difference might be due to the frequent prescription of broad spectrum antibiotic for HIV patients. The high prevalence of MDR enterococccal colonization in humans may lead to infection with reduced treatment options.

\section{Limitation of the study}

The isolated enterococcci were not indentified to species level.

\section{Conclusion}

The prevalence of VRE in clients attending the University of Gondar Hospital was 5.5\%. Patients with prior exposure to antibiotics for more than two weeks had higher colonization than their respective group. The presence of 11 (5.5\%) prevalence of VRE in this study signals the emergence of VRE in the study area. Therefore, rational use of antibiotics and more detailed study using phenotypic and genotypic methods are needed.

\section{Competing interests}

The authors declare no conflict of interest exists.

\section{Authors' contributions}

WA, ME and FM: conceived the idea, write the proposal, processes clinical samples, data analysis and draft the manuscript for publication. MT: assisted during sample processing. All the authors read and approved the manuscript.

\section{Acknowledgements}

The authors want to thank Mr. Solomon Checkol who sponsors the selective media and sent from USA to do this work. The department of Medical Microbiology of University of Gondar is acknowledged for giving space and different culture media to conduct this project. We want to extend our appreciation to Mr. Teklay and Mr. Abrham for their technical support during this project.

Received: 15 November 2013 Accepted: 18 February 2014 Published: 20 February 2014

\section{References}

1. Sood S, Das MM, Kapil A: Enterococcal infections \& antimicrobial resistance. Indian J Med Res 2008, 128:111-121.

2. Batistao DW, Gontijo-Filho PP, Conceicao N, de Oliveira AG, Ribas RM: Risk factors for vancomycin-resistant enterococci colonisation in critically ill patients. Mem Inst Oswaldo Cruz 2012, 107(1):57-63.

3. Tornieporth NG, Roberts RB, John J, Hafner A, Riley LW: Risk factors associated with Vancomycin-resistant enterococcus faecium infection or colonization in 145 matched case patients and control patients. Clin Infect Dis 1996, 23:767-772.

4. Arias CA, Murray BE: The rise of the Enterococcus: beyond vancomycin resistance. Nat Rev Microbiol 2013, 10(4):266-278.

5. Centers for Disease Control and Prevention Hospital Infection Control Practices Advisory Committee: Recommendations for preventing the spread of vancomycin resistance. Infect Control Hosp Epidemiol 1995, 44:1-13.

6. Achenbach C, Flores E, Ferrell P, Pitrak D, Weber SG: Prevalence of and risk factors for colonization with vancomycin-resistant Enterococcus among human immunodeficiency virus-positive outpatients. Infect Control Hosp Epidemiol 2006, 27:102-104.

7. Iwen PC, Kelly DM, Linder J, Hinrichs SH, Dominguez EA, Rupp ME: Change in prevalence and antibiotic resistance of Enterococcus species isolated 
from blood cultures over an 8-year period. Antimicrob Agents Chemother 1997, 41:494-495.

8. Mundy LM, Sahm DF, Gilmore MS: Relationship between enterococcal virulence and antimicrobial resistance. Clin Microbiol Rev 2000, 13:513-522.

9. Willems RJ, Top J, van Santen-Verheuvel M, Robinson DA, Coque TM, Baquero F, Grundmann H, Bonten MJ: Global spread of vancomycinresistant Enterococcus faecium from distinct nosocomial genetic complex. Emerg Infect Dis 2005, 11(6):821-828.

10. Federal Democratic Republic of Ethiopia Ministry of Health: National Training Package for Provider-Initiated HIV Testing and Counseling In., vol. 1. Addis Ababa: The Federal Democratic Republic of Ethiopia Ministry of Health; 2010:95-99.

11. Facklam RR, Washington JA II: Streptococcus and related catalasenegative gram-positive cocci. In Manual of clinical microbiology. Edited by Ballows A, William J, Hassler JR, Isenberg HD, Shadomy HJ. Washington DC: American Society for Microbiology; 1991:243-254.

12. Clinical and Laboratory Standards Institute: Methods for dilution antimicrobial susceptibility tests for bacteria that grow aerobically. 8th edition. Pennsylvania, USA: Wayne; 2009.

13. Dan M, Poche F, Leibson L, Smetana S, Priel I: Rectal colonization with vancomycin resistant enterococci among high risk patients in an Israeli hospital. J Hosp Infect 1999, 43:231-238.

14. Djahmi N, Boutet-Dubois A, Nedjai S, DEkhil M, Sotto A, Lavigne JP: Molecular epidemiology of Enterococcus spp. isolated in a university hospital in Algeria. Scand J Infect Dis 2012, 44(9):656-662.

15. Hijazi N, Elmanama AA, Al-Hindi A: Vancomycin-resistant Enterococci in fecal samples from hospitalized patients and non-hospitalized individuals in Gaza City. J Pub Health 2009, 17(4):243-249.

16. Kee SY, Park CW, Lee JE, Kwon YJ, Pyo HJ, Western Dialysis Physical Association, Kim WJ, Cheong HJ: Healthcare-associated risk factors of vancomycin-resistant Enterococci colonization among outpatients undergoing hemodialysis. Jpn J Infect Dis 2012, 65(1):57-60.

17. Al-Tonbary YA, Soliman OE, Sarhan MM, Hegazi MA, El-Ashry RA, El-Sharkawy AA, Salama OS, Yahya R: Nosocomial infections and fever of unknown origin in pediatric hematology/oncology unit: a retrospective annual study. World J Pediatr 2011, 7(1):60-64.

18. Abdel Rahman AT, Hafez SF, Abdelhakam SM, Ali-Eldin ZA, Esmat IM, Elsayed MS, Aboul-Fotouh A: Antimicrobial resistant bacteria among health care workers in intensive care units at Ain Shams University Hospitals. J Egypt Soc Parasitol 2010, 40(1):71-83.

19. Dhawan VK, Nachum R, Bhat N, Tolbert L, Agrawal M: Vancomycin resistant enterococcal colonization in nonhospitalized HIV-infected patients. West J Med 1998, 169:276-279.

20. Bekele B, Ashenafi M: Distribution of drug resistance among enterococci and salmonella from poultry and cattle in Ethiopia. Trop Anim Health Prod 2010, 42(5):857-864.

21. Murray BE: Vancomycin-resistant enterococcal infections. N Engl J Med 2000, 342:710-721

22. Shaghaghian S, Pourabbas B, Alborzi A, Askarian M, Mardaneh J: Vancomycin-resistant Entrococci colonization in chronic hemodialysis patients and its risk factors in southern Iran (2005-2006). Iran Red Crescent Med J 2012, 14:686-691.

23. DeLisle S, Perl TM: Vancomycin-resistant enterococci: a road map on how to prevent the emergence and transmission of antimicrobial resistance. Chest 2003, 123:5045-518S.

doi:10.1186/1471-2458-14-185

Cite this article as: Abebe et al:: Prevalence of vancomycin resistant Enterococci and associated risk factors among clients with and without HIV in Northwest Ethiopia: a cross-sectional study. BMC Public Health 2014 14:185.

\section{Submit your next manuscript to BioMed Central and take full advantage of:}

- Convenient online submission

- Thorough peer review

- No space constraints or color figure charges

- Immediate publication on acceptance

- Inclusion in PubMed, CAS, Scopus and Google Scholar

- Research which is freely available for redistribution

Submit your manuscript at www.biomedcentral.com/submit
Ciomed Central 